\title{
DE ONTWIKKELING VAN DE SIMULATIEMETHODE IN HET ECONOMISCH ONDERWIJS
}

\author{
door Drs. Th. P. van Hoorn
}

\section{\1. INLEIDING}

Evenals in vele andere wetenschappen neemt de toepassing van de simulatiemethode in de economie thans in snel tempo toe. Ofschoon de eerste meer markante voorbeelden van de simulatiemethode in het economisch onderwijs van omstreeks 1900 stammen, treedt de grote groei in de toepassing eigenlijk pas sinds het begin der vijftiger jaren op. Opmerkelijk is in dit verband, dat in die jaren en ook daarvoor reeds, veelal onafhankelijk van elkaar een aantal didactische methoden zijn ontwikkeld die alle duidelijke simulatiekenmerken dragen, die echter toen nog niet als zodanig werden onderkend. Pas zeer recent (tegen het einde van de vijftiger jaren) begon men het simuleren als gemeenschappelijke karaktertrek van deze onderwijsmethoden te zien. De woorden ,simuleren” en "simulatiemethode” $\mathrm{kwamen}$ in $\mathrm{zwang}$ en men ging zich intensief op hun didactische merites beraden. Het is kenmerkend, dat in het bekende boek van McNair c.s.: „The case method at the Harvard Business school" van $1954{ }^{1}$ ) het woord simulation maar een paar keer voorkomt. Thans, 10 jaar later, is het woord volledig ingeburgerd en worden er vele wetenschappelijke publicaties aan gewijd!

Dit betekent dat wij op dit moment ongetwijfeld nog op een relatief vroeg tijdstip in de geschiedenis van de simulatiemethode staan. De mogelijkheden worden thans in snel tempo verkend en onderkend. Op allerlei plaatsen duiken nieuwe vormen op. De richting waarin de ontwikkeling in de toekomst gaat is nog zeer onzeker. Dit brengt met zich, dat een analyse van haar ontwikkeling onvermijdelijk de sporen draagt van onvolledigheid.

Ofschoon iedereen het er over eens zal zijn dat simulatie nabootsing betekent, blijkt een definiëring van het begrip toch nogal wat problemen op te leveren ${ }^{2}$ ). In het kader van dit artikel heeft de simulatie een bij uitstek didactisch doel. Het betreft dus al die gevallen waarbij bepaalde - economisch geaarde - practijksituaties of werkzaamheden in een beschermde, geïsoleerde situatie in al dan niet vereenvoudigde vorm worden nagebootst teneinde de leerlingen in de gelegenheid te stellen zich in de door de docent gewenst geachte leerelementen te bekwamen. Wèlke aan de realiteit ontleende leerelementen de docent kiest en hoe hij deze structureert zal van de doelstelling van het onderwijs afhangen.

Zo gesteld is de formulering vrij ruim. Het zal nodig blijken nog een bepaalde verfijning aan te brengen, waarop ik hieronder nog terugkom.

Naast een beschrijving van het chronologisch verloop, hoe onvolledig deze in het hier toegemeten bestek ook moge zijn, wil ik eerst trachten een verklaring te zoeken voor de wijze waarop de verschillende varianten van de simulatiemethode ontstaan en vervolgens gegroeid zijn. Opkomst en ontwikkeling worden verklaarbaar als men ze beziet tegen de achtergrond van de educatieve behoeften en opvattingen in het betreffende tijdvak.

1) M. P. Mc Nair en A. C. Hersum: The case method at the Harvard Business school. New York - London 1954.

$\left.{ }^{2}\right)$ Vgl. Richard E. Dawson: Simulation in the social sciences in: Simulation in social science: Readings, Harold Guetzkow Editor. Englewood Cliffs 1962. 
Sinds de vorige eeuw is de structuur van onze voortbrenging ingrijpend gewijzigd en daarmede de problemen waarmede leidinggevende functionarissen in bedrijfsleven en overheid zich bezig moeten houden. Als gevolg van de toenemende dynamiek en gecompliceerdheid van onze maatschappij begon er geleidelijk een steeds duidelijker wordende kloof te ontstaan tussen de practijk en de theorie van het economisch onderwijs. Men is zich in onderwijskringen in de loop der jaren diepgaand gaan beraden op de ontwikkeling van methoden die aan de hier gesignaleerde behoefte tegemoet konden komen.

Men moet het simuleren in het onderwijs zien als een methode die ten doel heeft de kloof tussen theorie en practijk te overbruggen. Men bouwt als het ware een tussenstation tussen beiden waarin de leerling kan oefenen en tijdens en na de oefening zijn ervaringen kan veralgemenen. De verscheidenheid aan practijksituaties die op deze wijze nagebootst kunnen worden heeft geleid tot de ontwikkeling van een groot aantal varianten van de simulatiemethode, afkomstig uit verschillende wetenschappen.

\section{\$2. EDUCATIEVE BEHOEFTEN EN OPVATTINGEN}

\section{Enkele achtergronden van opkomst en ontwikkeling van de simulatie}

Het onderwijs in de economie heeft lange tijd een overwegend theoretisch-verklarend karakter behouden. Vóór 1900 behandelde de economie, veelal als onderdeel van de juridische opleiding, voornamelijk ,algemene" problemen zoals de prijs- en inkomensvorming. In die tijd verheugt het bedrijf zich zich nog maar sporadisch in de belangstelling van economen. Hierin komt na 1910 langzaam verandering als geleidelijk tot de stichting van aparte economische faculteiten en hogescholen wordt overgegaan. Het bedrijf werd nog nauwelijks gezien als een probleemgebied van economische aard. Leiding geven, beslissingen nemen e.d. werden beschouwd als een kunst, niet als een vak. Er werd geen behoefte gevoeld aan een op dit leiden gerichte opleiding, ofschoon toch de problemen reeds moeilijk genoeg waren. Vorming van leiders diende plaats te vinden langs de weg van het zelf opdoen van ervaring in het bedrijfsleven, waartoe men liefst verschillende functies diende te vervullen.

In deze periode leidden universiteiten en hogescholen wetenschapsmensen op, geen practici. De traditionele onderwijsmethoden, hoorcollege en literatuurstudie voldeden toentertijd ten volle aan deze doelstelling. Er kon nog niet van een kloof tussen theorie en practijk gesproken worden en er bestond toen naar mijn mening dan ook geen behoefte aan simulatie.

Hierop moet één uitzondering gemaakt worden. Het enige onderwijs met een economische inslag dat zich op het bedrijf richt is dat in boekhouden en handelsrekenen. Beide vakken bedienen zich in de loop van de $19 \mathrm{e}$ eeuw reeds van eenvoudige vraagstukken. Men zou dit een eerste spoor van simulatie kunnen noemen. Het is immers een op de practijk gerichte nabootsing van werkzaamheden in een beschermde oefensituatie. Het betreft hier echter een wel zeer specifiek geval: mits goed geredigeerd is er slechts één antwoord op de vraagstukken mogelijk. $\mathrm{Er}$ is geen ruimte voor creativiteit of inventiviteit, noch ook voor beslissen op grond van werkelijke alternatieven. Het is een vaardigheidsimulatie van in hoofdzaak technisch-uitvoerende aard. Niettemin is hiermede een eerste kiem aanwezig, waaruit zich later andere simulatiemethoden zullen ontwikkelen. 
De behoefte aan in de practijk bruikbare functionarissen was voor de beide vakken, boekhouden en handelsrekenen, reeds geconstateerd. Daarna waren de voor de uitoefening van de functie gewenste practische vaardigheden in een doceerbare vorm vastgelegd. Beide elementen, een duidelijk gesignaleerde behoefte en de mogelijkheid tot stylering van de leerstof zijn voorwaarde voor een verdere ontwikkeling van de simulatiemethode. Deze behoefte ging zich nu in de loop der jaren steeds sterker manifesteren bij het leiden van bedrijven. De opvatting dat men dit leiding geven kon leren door het uitsluitend opdoen van ervaring kon minder standhouden doordat de maatschappij steeds gecompliceerder werd. Immers, naarmate veranderingen sneller tot stand komen, wordt de waarde van de opgedane ervaring geringer. Het gaat er juist om eigenschappen te ontwikkelen waarmede men de als gevolg van de veranderingen optredende vraagstukken op de juiste wijze kan oplossen. Oordeelsvermogen, creativiteit, flexibiliteit, inzicht en beslissingsvermogen worden dan verlangd, eigenschappen die men met behulp van de traditionele onderwijsmethoden onvoldoende kon ontwikkelen. De kloof tussen theorie en practijk begon duidelijk te worden.

In deze lijn doordenkend kwam men in de V.S. op het idee geselecteerde practijkervaring in gestyleerde vorm aan de student voor te leggen. Daardoor werd het in principe mogelijk de ervaring te systematiseren en in een bepaald theoretisch kader te brengen en zodoende de band tussen theorie en practijk te versterken.

De business-case-study, in 1911 voor het eerst in Harvard geïntroduceerd ${ }^{3}$ ) en sindsdien wijd verbreid, betekende een zeer wezenlijke ontwikkeling. Belangrijk is dat hier gepoogd wordt een essentieel ander leerproces tot stand te brengen dan bij het boekhoudonderwijs. In een case kan men een beslissing te nemen krijgen ten aanzien van de keuze tussen b.v. liquidatie, reorganisatie of fusie, dan wel tussenvormen daarvan. Het onderwijs krijgt daarmee een geheel andere doelstelling, namelijk beslissingen nemen onder critische omstandigheden, waarbij inzicht en oordeelsvorming essentieel zijn. Men moet daarom mijns inziens los van de methode van simulatie (case, spel etc.) een onderscheid maken naar type van simulatie, parallel met de onderscheiding naar onderwijsdoelstellingen ${ }^{4}$ ). In dit kader kan men derhalve onderscheiden naar vaardigheids-, inzicht- en oordeelsvorming-simulatie. De na de case ontwikkelde simulatiemethoden, die ik in ander verband nog zal bespreken, tonen alle een of meer van de genoemde simulatieelementen.

Met de behoefte wijzigt zich immers de doelstelling van de simulatie. Het ligt voor de hand dat men dan ook naar nieuwe methoden gaat zoeken om de gewenste practijkaanpassing te bereiken. In dit verband is de opkomst van de sociale zusterwetenschappen - veelal als behavioural sciences aangeduid - van grote betekenis. Men gaat hoe langer hoe meer inzien dat het leiden van een organisatie in feite ook of juist een vraagstuk is van het leidinggeven aan mensen. Sociologie, sociale psychologie en bedrijfspsychologie gaan zich op de organisatie richten en daarmede ontstaat een groot aantal raakvlakken met de economie. De grenzen vervagen enigszins. Management wordt multidisciplinair, maar daarmede wordt

3) Vgl. Melvin T. Copeland: The genesis of the case method in business instruction. In M. P. Mc Nair en A. C. Hersum: The case method at the Harvard Business school. New York - London 1954. Pag. 25 e.v.

†) Vgl. Th. P. van Hoorn: Beslissingsspelen. Enkele educatieve aspecten van hun toepassing. T.E.D. Februari 1964, pags. $63 / 64$.

m a b blz. 61 
gestimuleerd dat bij de sociale zusterwetenschappen ontwikkelde methoden ook voor het economisch onderwijs interessant worden (rollenspel).

De opkomst van de sociale zusterwetenschappen is nog in ander verband didactisch van betekenis. Het aldaar verrichte onderzoek naar de mate van gemotiveerdheid van mensen bij het leren heeft ons inzicht hierin zeer vergroot. De plaatsing in de nagebootste practijksituatie verlangt immers altijd een bepaalde prestatie van de leerling: het nemen van een beslissing, het voeren van een gesprek, het uitspreken van een oordeel etc. Het resultaat hiervan is de leerling geenszins onverschillig. Er ontstaat een persoonlijke gebondenheid aan de prestatie en hierdoor wordt de belangstelling en de concentratie op het leerproces versterkt. Vooral het laatste decennium blijkt op grond van het groeiend inzicht in de motivatie cen toenemende voorkeur voor simulatiemethoden te ontstaan, zelfs daar waar men tot voor kort veelvuldig van niet-simulatieve methoden gebruik pleegde te maken.

De lijn van de toenemende dynamiek laat zich verder doortrekken. Extern zowel als intern schept de noodzaak van het opvangen van en tegemoettreden aan de veranderingen een steeds grotere behoefte aan adaequate opleiding. Uit deze behoefte kunnen de opkomst van het beslissingsspel en van de nieuwe variant van de case, de "dynamische case" 5 ), verklaard worden, die beide beogen veranderingen tijdens de oefening te introduceren. De snelle groei leidt tot een voortdurend qualitatief tekort aan mensen, echter niet uitsluitend op vakgebied. Meer en meer komt men tot het inzicht dat menselijke karaktereigenschappen voor het functioneren van de organisatie van essentieel belang zijn. Bij de opleiding komt het zwaartepunt geleidelijk meer op persoonlijkheidsontwikkeling te liggen. Ook het modern personeelsbeleid begint in deze richting te denken ${ }^{6}$ ). Steeds meer aandacht wordt aan overleg, samenwerking, leiding geven, communicatie en dergelijke thema's gegeven. Deze onderwerpen hebben een bij uitstek practisch karakter. Het is dan ook niet te verwonderen, dat men hier in toenemende mate zijn toevlucht heeft genomen tot simulatie-oefeningen. Het leren moet hier in hoofdzak komen uit het doen, niet uit het horen of lezen. Een intensieve uitwisscling tussen de economie en haar sociale zusterwetenschappen heeft inmiddels een groot aantal, o.a. discussie-, communicatie- en onderhandelingsoefeningen, opgeleverd, die in toenemende mate in opleidingen worden geïntroduceerd. Het traditioneel opleidingspatroon is sterk aan het veranderen zowel qua inhoud als qua methode.

\section{\$3. ONTSTAANSGEBIEDEN EN TOEPASSINGSTERREINEN}

Bij de ontwikkeling van de simulatiemethode is men in de Verenigde Staten bijzonder actief geweest. Een groot deel van de in het navolgende chronologische overzicht opgenomen simulatievormen blijkt daar zijn oorsprong te vinden. Pas in de laatste ca. 10 jaar is Europa en ook Japan zich meer met dit terrein gaan bezighouden. Ongetwijfeld heeft hierbij een belangrijke rol gespeeld dat de economische ontwikkeling in de V.S. op die in West-Europa vooruitgelopen is.

5) Vgl. Kalman J. Cohen en Eric Rhenman: The role of managementgames in education and research, in Management science vol $7 \mathrm{nr}$. 2, Jan. 1961, pag. 153 e.v.

6) Vgl. J. G. Bavinck: Het personeelbeleid van vandaag - publicatie van het C.S.W.V. - Amsterdam 1961 en J. J. M. Penders: Kadervorming in de Industrie. Hoofdstuk II. Utrecht/Antwerpen 1962.

$\mathrm{m}$ a b blz. 62 
Daarnaast is de opleiding in de V.S. veelal directer op de practijk gericht dan bij ons ${ }^{7}$ ). Beide factoren hebben stellig een stimulerende invloed op de introductie van de verschillende simulatievormen in het onderwijs in de V.S. gehad.

Opmerkelijk is, dat de simulatiemethode bij de bedrijfseconomische vakken zoveel meer ingang heeft gevonden dan bij de sociaal-economische. Er is hier duidelijk een eenzijdige verdeling. Dit is stellig mede een gevolg van het feit dat het bedrijfseconomisch onderwijs in het algemeen makkelijker op de practijk te richten is, terwijl bepaalde bedrijfseconomische problemen zich wellicht wat eenvoudiger laten simuleren dan de sociaal-economische. Daarnaast valt management traditioneel onder de bedrijfseconomie, terwijl de vraagstukken van het leiding geven in de overheidssector en het bedrijfsleven in wezen niet zeer verschillend zijn. De laatste jaren worden er bovendien steeds meer cases en spelen op sociaal-economisch gebied ontwikkeld (o.a. in Pittsburg).

Het tempo van invoering van de verschillende simulatiemethoden na de eerste publicaties hierover is in een aantal gevallen vrij traag geweest. De introductie van simulatie-oefeningen in het onderwijs veroorzaakt een fundamentele wijziging in de verhouding docent-leerling en vergt een totaal andere instelling van beiden. De docent onderwijst niet meer op de traditionele wijze, doch hij creëert een situatie waarin de leerling door zijn eigen verrichtingen en ervaringen kan leren, welk leerproces later nog wordt versterkt met behulp van een nabespreking door de docent. De activiteit gaat dus grotendeels van docent op leerling over. De Amerikanen spreken hier van een "democratische" methode, omdat iedere leerling in principe kan bijdragen tot de oplossing. De docenten moeten deze situaties effectief kunnen hanteren. Dit vraagt een vrij grote omstelling t.o.v. de traditionele situatie ${ }^{8}$ ) en blijkt vooral bij oudere docenten nogal eens moeilijkheden op te leveren. Daarnaast vragen de meeste simulatie-oefeningen vrij veel tijd, vooral als men aan de aansluitende evaluatie voldoende aandacht wil besteden. Beide omstandigheden leiden ertoe dat een invoering in universitaire opleidingen met traditionele collegeroosters dik wijls op bezwaren stuit.

Vooral in Europa maar ook in de V.S. zien we dan ook over het algemeen een geleidelijke invoering van de simulatie bij het economisch hoger onderwijs. Nog slechts enkele europese instellingen hebben simulatie-oefeningen in enige omvang in her onderwijs geïntroduceerd ${ }^{9}$ ).

Anders ligt het uit de aard der zaak bij opleidingen binnen het bedrijfsleven. Deze zijn eensdeels sterker op de practijk gericht, anderdeels minder rigide van structuur en bieden daardoor in principe meer mogelijkheden voor het invoeren van simulatie. Het valt daarbij op dat het bedrijfsleven actief is bij een uitbreiding van het toepassingsgebied, doordat niet alleen bij de opleiding van hogere leidinggevende functionarissen - waartoe de simulatie tot nog toe grotendeels beperkt bleef - doch ook bij bazen- en zelfs arbeidersopleidingen bepaalde simulatievormen geïntroduceerd worden.

7) Vgl. Rapport: Universitaire opleiding voor leiding en organisatie van bedrijven, van de commissie opvoering productiviteit van de S.E.R. pag. 10 en 11.

${ }^{8}$ ) Vgl. G. Dahlke: Das Wesen der Fallmethode, pag. 18/19 in: Die Fallmethode. R.K.W.Schriftenreihe Betriebsführung und Fortbildung. BF3, Frankfurt/Main, 1963.

$\left.{ }^{9}\right)$ o.a. College of Advanced Technology, Birmingham U.K. Het College of Commerce, Leeds U.K. en de Freie Universität, Berlin. 


\section{$\$ 4$. ENKELE CHRONOLOGISCHE GEGEVENS}

Het maken van een indeling in perioden of fasen die aan de ontwikkeling recht doet wedervaren is bijzonder moeilijk. Ongetwiifeld is de reeds genoemde principiële beslissing van de Harvard Business School in 1911 om een op de practijk gerichte business opleiding te starten ondersteund door systematische know how in de vorm van cases van verstrekkende betekenis geweest voor de ontwikkeling van de simulatiemethode. Interessant is het overigens dat het Nederlands Instituut van Accountants de Amerikanen wat de intentie betreft eigenlijk voor geweest is: in "De Accountant" van ianuari 1897 komt een examenongave voor die reeds onmiskenbaar cen case-karakter heeft. Het gebruik van deze case-achtige vraagstukken is door het N.J.v.A. tot op de dag van heden met succes gehandhaafd.

De ontwikkeling en introductie van de case-methode nam gcruime tijd in de V.S. In de iaren tot 1940 ontatond er geleidelijk een grote variëteit cases aangebast aan meer specifieke onderwiisdoelste!lingen, niet alleen voor de verschillende vakken (verkoop. productie, financicring etc.), maar ook gedifferenticerd naar bedriifstakken en binnen deze weer naar deelnroblemen hierin.

Omstreeks 1940 wordt de case-methode ook geïntroduceerd bij de zogenaamde human relations-vakken. Van deze ontwikleling gat de economische opleiding in de vijftiger iaren steeds meer profiteren als de betrekkingen met de sociale zusterwetenschappen in het kader van de management-opleiding hechter worden $\left.{ }^{10}\right)$.

Intussen is in de loop van de dertiger iaren een nieuwe simulatievorm in opkomst. De Spaanse psychiater Moréno heeft zijn sociodrama en psychodrama geintroducecrd, die later als rollenspel vooral van belang zullen worden om mensen meer inzicht te geven in de invloed die hun eigen houding en instelling hebben op anderen binnen een groep ${ }^{11}$ ). Ook hier zal het niettemin tot na de $2 e$ wereldoorlog duren voordat invoering op enige schaal op universiteiten en bedrijfscursussen plaatsvindt.

Tijdens de $2 \mathrm{e}$ wereldoorlog, en in de cerste jaren daarna verschijnen er geen belangrijke simulatievarianten in het onderwijs. Niettemin zijn er op ander gebied enkele ontwikkelingen aan de gang dic voor de onderwijssimulatie later van groot belang zullen blijken te zijn, namelijk de uitbouw van de militaire simulatic en de opkomst van de operations research voor beslissingsvoorbereiding, welke later de bouwstenen voor het beslissingsspel zullen vormen.

In de iaren '50 krijgt de ontwikkeling cen enorme stoot. In 1954 verschijnen de eerste artikelen van Paul en Faith Pirors, dic met hun incident-proces cen nieuwe vorm introduceren die tussen case en rollenspel in staat ${ }^{12}$ ). Hierin is vooral het diagnose-karakter belangrijk, waardoor het ook als een variant van de case voor de cronomische opleiding van betekenis wordt.

De American Management Association publiceert in 1957 het eerste beslissings-

10) F. T. Roethlisberger and others: Training for human relations - an Interim report, Boston 1954 en Norman R. F. Maier: Principles of human relations - applications to management, New York - Londen 1952.

11) vgl. T. L. Moreno: Who shall survive? Beacon House Inc., Beacon, N.Y. 1953.

12) Paul and Faith Pigors: Case method on the spot en Paul and Faith Pigors: The incident process, learning by doing. Adult Leadership, Dec. 1954 en Jan. 1955. 
spel na diepgaande bestudering van de reeds lang gebruikte militaire spelen ${ }^{13}$ ). Hiermede werd tegemoet gekomen aan de wens om een dynamische opleidingssituatie te creëren, waarbij men met de resultaten van de eigen beslissingen verder moest leven, hetgeen men bij de case zozeer miste. Het beslissingsspel vond zijn weg naar de opleidingen in een zeer snel tempo en ongetwijfeld heeft dit velen de ogen geopend voor de didactische mogelijkheden van simulatie. Hierdoor kon het tevens wegbereider worden voor andere methoden die nog niet toegepast waren. De grote opmars van de simulatie is met het beslissingsspel begonnen. Een weg die bij de case ca. 20 jaar in beslag nam werd hier in ca. 5 jaar afgelegd. In een ongelooflijk tempo verschenen er talloze nieuwe spelen, op de meest uiteenlopende terreinen betrekking hebbende. In 1958 en 1959 wordt het „functionele" gebied ontdekt (bestelniveau, productieplanning e.d.) ${ }^{14}$ ) en omstreeks 1960 was het gehele gebied wel bepaald, zij het dat er nog steeds zeer veel nieuwe spelen tot stand komen ${ }^{15}$ ).

Parallel hiermede komt in dezelfde periode een andere vorm tot ontwikkeling eveneens van militaire oorsprong. Aanvankelijk als test opgezet voor een geschiktheidsonderzoek bij de NIKE-AJAX luchtdoel-batterijen werd deze later uitgewerkt tot het postbakje, dat sinds 1960 veel ingang in Europa begint te krijgen ${ }^{16}$ ).

Omstreeks 1960 ontstaat - voorlopig nog in de politiek - een toenemende belangstelling voor de problematiek van de onderhandeling. Dit heeft inmiddels tot de totstandkoming van verschillende politieke doch ook economische onderhandelingsspelen geleid ${ }^{17}$ ). Hetzelfde kan gezegd worden van de communicatie, personeelsselectie en dergelijke onderwerpen.

\section{\$5. CONCLUSIE}

Het terrein begint op dit moment zo wijd te worden, dat het niet zinvol is te pogen alles nog binnen een kort artikel te vatten. Naarmate de idee van simulatie gemeengoed begint te worden en een zekere vaardigheid ontstaat in simulatief denken, zijn er eigenlijk nauwelijks nog grenzen gesteld aan de toepassingsmogelijkheden. Ook dit wordt een questie van creativiteit. Het belangrijkste gaat op den duur vrij zeker het zuiver diagnostiseren van de educatieve behoeften, alsmede het op een juiste wijze hanteren van de gecreëerde situatie worden.

De methode moet uitsluitend middel tot het doel zijn. In dat verband moet men alle stellingen pro en contra bepaalde methoden bezien.

In de naaste toekomst zal ongetwijfeld een nog verdere differentiatie in ontwerp en in hantering van de verschillende simulatiemethoden gewenst blijken. $\mathrm{Er}$ is op dit terrein een uiterst boeiende ontwikkeling aan de gang, waarvan wij het verdere verloop met spanning tegemoet kunnen zien.

13) Franc M. Ricciardi et al.; Top Management decision - simulation: The A. M. A. Approach. New York: American Management Association Inc. 1957.

14) vgl. J. R. Greene en R. L. Sisson; Dynamic Management Decision Games, New York 1959. en de Nederlandse bewerking hiervan: A. H. Hulshof en I. Ykel: Beslissingsspelen, Alphen aan de Rijn 1962.

15) vgl. W. Rohn: Führungsentscheidungen im Unternehmensplanspiel, Essen 1964, waarin meer dan 200 in gebruik zijnde spelen zijn gerubriceerd.

16) Charles D. Smith: What's in the box, Doc? Training Directors Journal Jan. '61.

17) vgl. Harold Guetzkow en anderen: Simulation in international Relations. Developments for research and teaching. Englewood Cliffs, N.J. 1963.

m a b blz. 65 